\title{
Esophageal cancer responsive to the combination of immune cell therapy and low-dose nivolumab: two case reports
}

Rishu Takimoto ${ }^{1,2^{*}}$, Takashi Kamigaki ${ }^{1,2}$, Takuji Gotoda ${ }^{3}$,Toshimi Takahashi ${ }^{3}$, Sachiko Okada ${ }^{1}$, Hiroshi Ibe ${ }^{1}$, Eri Oguma ${ }^{1}$ and Shigenori Goto ${ }^{1,2}$

\begin{abstract}
Background: Blocking the programmed death 1 pathway by immune checkpoint inhibitors induces dramatic antitumor activity in patients with malignant tumors. However, the clinical response to immune checkpoint inhibitors remains limited owing to the patients' immunological status, such as the number of lymphocytes, programmed death ligand 1 expression, and tumor mutation burden. In this study, we successfully treated two patients with advanced esophageal cancer who responded to the combination of adoptive immune cell therapy and a low-dose immune checkpoint inhibitor, nivolumab.
\end{abstract}

Case presentation: Two Asian (Japanese) patients with advanced esophageal cancer who were resistant to conventional chemoradiation therapy were referred to our hospital for immune therapy. Case 1 was a 66-year-old woman who was diagnosed as having esophageal cancer. She received concurrent chemoradiation therapy and then underwent subtotal esophagectomy, after which she became cancer free. However, she relapsed, and cancer cells were found in the lung and lymph nodes 6 months later. She enrolled in a clinical trial at our institution (clinical trial number UMIN000028756). She received adoptive immune cell therapy twice at a 2-week interval followed by lowdose nivolumab with adoptive immune cell therapy four times at 2-week intervals. A follow-up computed tomography scan showed partial response, with mass reduction of the metastatic lung and mediastinal lesions. Case 2 was a 77-year-old man. He received concurrent chemoradiation therapy with fluoropyrimidine/platinum, and gastroscopy revealed complete remission of esophageal cancer. He was disease free for 5 months, but routine computed tomography revealed multiple metastases in his lungs and lymph nodes. He visited our clinic to receive adoptive immune cell therapy and immune checkpoint inhibitor combination therapy. Radiographic evidence showed continuous improvement of lesions. There was no evidence of severe adverse events during the combination therapy.

Conclusion: The combination of adoptive immune cell therapy and an immune checkpoint inhibitor might be a possible treatment strategy for advanced esophageal cancer.

Trial registration UMIN000028756. Registered 14 September 2017

Keywords: Immune cell therapy, Esophageal cancer, Immune checkpoint inhibitor, aßT cell therapy, Dendritic cell vaccine

*Correspondence: takimoto@j-immunother.com

${ }^{1}$ Seta Clinic Group, New Surugadai Bldg. 3F, 2-1-45 Kandasurugadai, Chiyoda-ku, Tokyo 101-0062, Japan

Full list of author information is available at the end of the article

\section{Background}

Esophageal cancer is an aggressive malignancy and the most common cause of cancer-related death worldwide [1]. Although treatment strategies such as surgery, original author(s) and the source, provide a link to the Creative Commons licence, and indicate if changes were made. The images or other third party material in this article are included in the article's Creative Commons licence, unless indicated otherwise in a credit line to the material. If material is not included in the article's Creative Commons licence and your intended use is not permitted by statutory regulation or exceeds the permitted use, you will need to obtain permission directly from the copyright holder. To view a copy of this licence, visit http://creativecommons.org/licenses/by/4.0/. The Creative Commons Public Domain Dedication waiver (http://creativeco mmons.org/publicdomain/zero/1.0/) applies to the data made available in this article, unless otherwise stated in a credit line to the data. 
chemotherapy, radiotherapy, and chemoradiotherapy have been developed in recent years, the prognosis for patients with recurrent or advanced-stage esophageal cancer remains poor [2]. The limited improvement in treatment outcome obtained by conventional therapies has prompted the search for innovative strategies for the treatment of this cancer, especially molecular or immune-targeting treatments.

The programmed death 1 (PD-1) pathway serves as a checkpoint to limit T-cell-mediated immune responses. Two ligands, programmed death ligand 1 (PD-L1) and programmed death ligand 2 (PDL-L2), engage the PD-1 receptor and induce PD-1 signaling and associated T-cell exhaustion, resulting in reversible inhibition of $\mathrm{T}$-cell activation and proliferation [3]. Tumor cells can coopt the PD-1 pathway to evade immune responses by expressing PD-L1 on the cell surface and engaging PD-1 receptor-positive immune effector cells [4]. Thus, PD-1 and PD-L1 have attracted considerable attention for their roles in tumor immunology and as immune-based therapeutic targets $[3,5]$. A number of clinical trials of PD-1/ PD-L1 signal-blockade agents as immune checkpoint inhibitors (ICIs) have recently demonstrated dramatic antitumor efficacy in patients with numerous types of malignancy, including esophageal cancer [6,7].

Although PD-L1 expression in tumor tissues prior to treatment correlates with clinical outcomes, the density of tumor-infiltrating lymphocytes (TILs) in the invaded margin of the tumor may better predict the response to anti-PD-1/PD-L1 therapy [8]. Recent research has shown four different types of tumor microenvironment based on the presence or absence of TILs and PD-L1 expression [9]. Tumors that are both PD-L1 and TIL positive are most likely to benefit from single-agent anti-PD-1/ PD-L1 blockade because such tumors possess preexisting TILs that are turned off by PD-L1 engagement. Thus, better understanding of PD-L1 expression and TIL status in esophageal cancer tissues may have considerable clinical implications.

Adoptive T-cell therapy using TILs has been found to mediate durable, complete cancer regression in patients with melanoma and epithelial cancers [10-12]. Collectively, these responses were likely based on the recognition of unique, patient-specific mutated neoantigens through the T-cell receptor (TCR) [12]. However, isolation of TILs from cancer tissue is not always feasible. It was recently demonstrated that peripheral blood lymphocytes contained TIL-like cells recognizing tumorspecific antigens and could be a source of noninvasive options for immune cell therapy [13]. Previously, we and others reported that adoptive T-cell therapy using peripheral blood mononuclear cells (adoptive cell therapy, ACT), which are activated and proliferated through a culture process involving stimulation with an immobilized anti-CD-3 antibody and interleukin-2 (IL-2), has shown certain efficacy against various cancers without severe adverse events $[14,15]$, indicating that the efficacy of ACT might partially be derived from TILs associated with peripheral blood cells.

Although ICIs have great potential for cancer immunotherapy, their efficacy is still limited by some toxicities. Synergies between ICI therapy and other immunotherapies including cancer vaccines or ACT are currently being investigated in several clinical trials [15]. Here, we report the cases of two patients with advanced esophageal cancer who were successfully treated and responded to the combination of $\mathrm{ACT}$ and an ICI, nivolumab, suggesting that this combination might be a possible treatment strategy for advanced esophageal cancer.

\section{Case presentation}

Case 1

A female Asian (Japanese) patient was diagnosed as having esophageal cancer in February 2016 at 66 years of age. Biopsy and computed tomography $(\mathrm{CT})$ revealed squamous cell carcinoma of the esophagus at clinical stage IV (UICC, T4N2M0). She received concurrent chemoradiation therapy (CCRT) with fluoropyrimidine/platinum from March to April 2016, then underwent subtotal esophagectomy in June 2016. Histopathological analysis of surgical tumor specimens revealed that her esophageal cancer was at clinical stage II (UICC, T3NOM0). She remained disease free until November 2016, when routine CT revealed a new pulmonary nodule and mediastinal lymph node swelling, $2.0 \mathrm{~cm}$ in diameter, in her left lung. She visited our clinic to receive ACT in December 2016 after radiotherapy for the lymph node metastasis in her lung from January to February 2017. During radiotherapy, she also received ACT using $\alpha \beta \mathrm{T}$ lymphocytes four times at 2-3-week intervals until April 2017. Then chemotherapy using fluoropyrimidine/platinum/docetaxel was administered until January 2018. However, routine CT revealed multiple lung metastases in February 2018. In July 2018, she enrolled in a clinical trial at our institution (clinical trial number UMIN000028756) (Fig. 1a). Before starting the clinical trial, we evaluated PD-L1 expression level using her tumor specimens and found that the PD-L1 expression level in the tumor tissue was less than $1 \%$. The tumor was negative for microsatellite instability (MSI; data not shown). She received ACT twice at a 2-week interval, followed by nivolumab at a dose of $0.3 \mathrm{mg} / \mathrm{kg}$ body weight with ACT four times at 2-week intervals, as part of induction therapy. A follow-up CT scan on 19 September 2018 (9 weeks after nivolumab initiation) showed partial response, with $48 \%$ mass reduction of the lung metastases and 


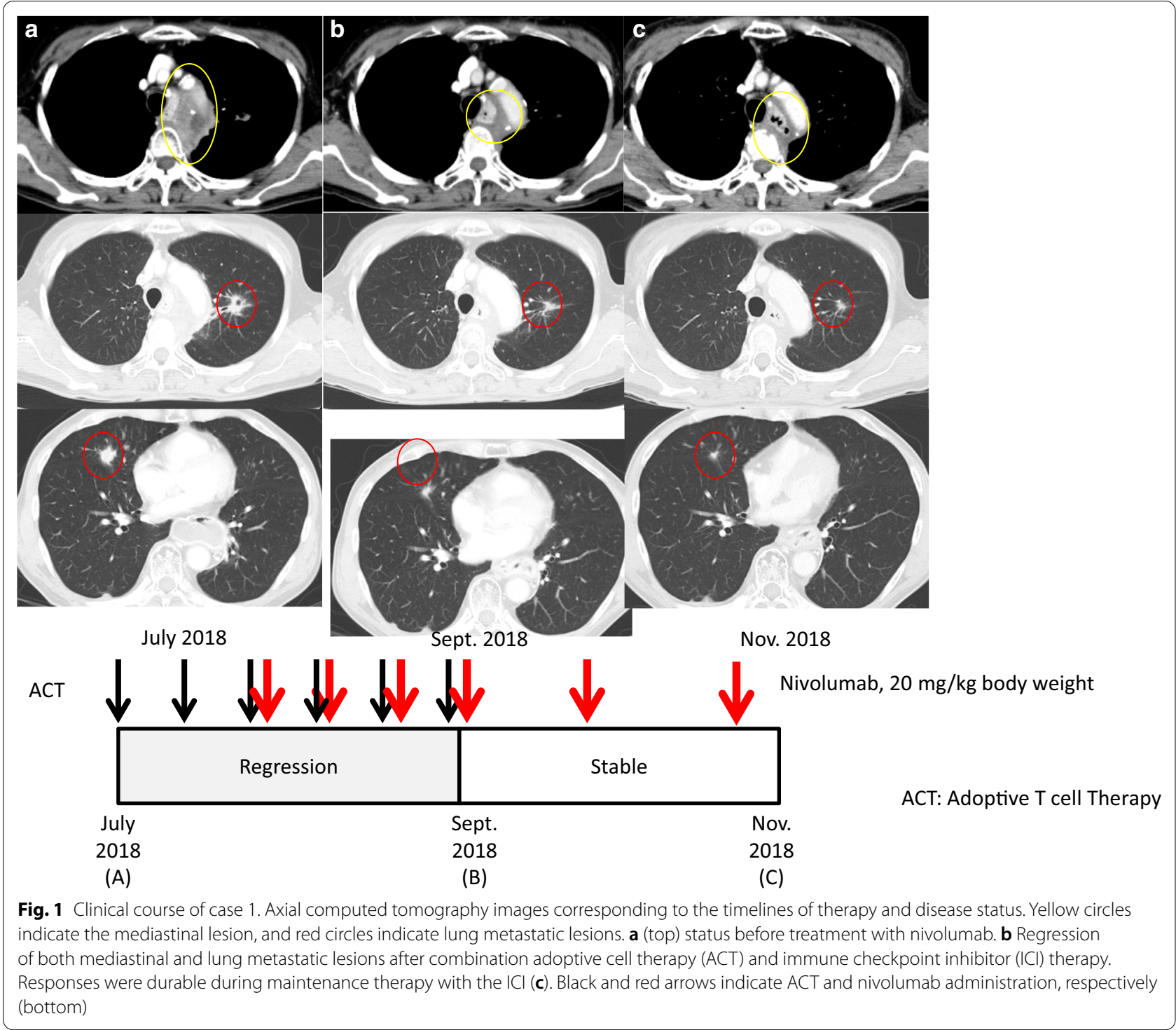

mediastinal lesion (Fig. 1b). She was allowed to continue with nivolumab treatment at a dose of $40 \mathrm{mg} / \mathrm{kg}$ body weight as maintenance therapy at 3-week intervals. Over her clinical course in 2018, there was radiographic evidence of slight improvement (Fig. 1c), and maintenance nivolumab therapy was continued because the patient was clinically well and alive. Mild, asymptomatic hypothyroidism developed, which required thyroid hormone supplementation, but she showed no other clinically significant treatment-related toxicity.

\section{Case 2}

A male Asian (Japanese) patient was diagnosed as having esophageal cancer in June 2016 at 77 years of age. CT and biopsy of specimens revealed squamous carcinoma of the esophagus at clinical stage IV (UICC, T4N2M1). He received CCRT with fluoropyrimidine/platinum from July to November 2017. In December 2017, gastroscopy revealed complete remission of esophageal cancer. $\mathrm{He}$ remained disease free until April 2018, when routine CT revealed multiple metastases in his bilateral lungs and lymph nodes of the right hilum (Fig. 2a). He was administered docetaxel as second-line chemotherapy from May to September 2018, but his lung metastases were found to have progressed (Fig. 2b). He visited our clinic to receive ACT in October 2018, followed by ACT using $\alpha \beta T$ lymphocytes three times at 2-3-week intervals until December 2018. He then received dendritic cells (DCs) pulsed with MUC1, MAGE3, and survivin, which were expressed on his tumor cells as tumor antigens, 12 times 


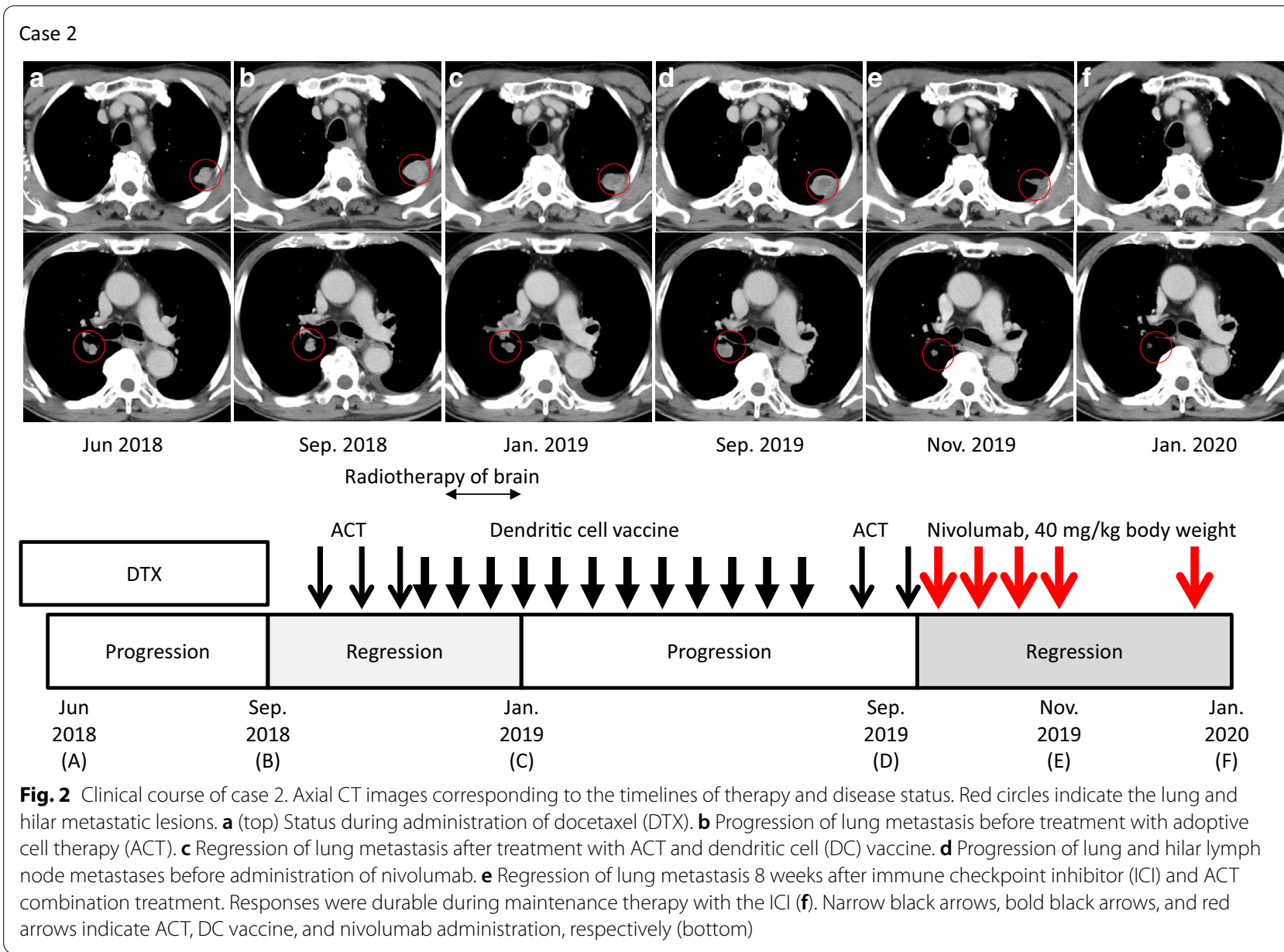

at 2-3-week intervals from 26 December 2018 to 28 June 2019 (Fig. 2). During ACT and pulsed DC therapy, he developed brain metastasis in November 2018 and underwent stereotactic radiosurgery for brain metastasis. Routine CT revealed that the sizes of multiple lung and lymph node metastatic lesions were reduced, which were evaluated as partial response on the basis of Response Evaluation Criteria in Solid Tumors (RECIST) version 1.1 in January 2019 (Fig. 2c). Furthermore, the sizes of brain metastatic lesions were decreased in April 2019. In September 2019, follow-up CT revealed regrowth of metastatic lesions in the lung and hilar lymph nodes, and he started to receive ACT once a month (Fig. 2d). Immunohistochemical staining revealed that the PD-L1 expression level in the tumor was $1 \%$, and the tumor was negative for MSI (data not shown). Following ACT, he received nivolumab at a dose of $0.6 \mathrm{mg} / \mathrm{kg}$ body weight four times at 2-week intervals as part of induction therapy. A follow-up CT scan on 27 November 2019 (8 weeks after nivolumab initiation) showed partial response, with $60 \%$ reduction of the lung mass and hilar lymph node swelling (Fig. 2e). He was allowed to continue with nivolumab treatment at a dose of $40 \mathrm{mg} / \mathrm{kg}$ body weight as maintenance therapy at 3-week intervals. Over his clinical course in 2019, radiographic evidence showed continuous improvement of lesions, and his treatment was continued with maintenance nivolumab therapy (Fig. 2f) because the patient was clinically well and alive. There was no evidence of adverse events during combination therapy.

Flow cytometric analysis of patients' peripheral blood mononuclear cells before and after combination immunotherapy with ACT and ICI

The total number of cells used for ACT ranged from 7.3 to $10.9 \times 10^{9}$ (average $8.3 \pm 1.7 \times 10^{9}$ cells/infusion) in case 1 and from 3.9 to $7.8 \times 10^{9}$ (average $6.1 \pm 1.7 \times 10^{9}$ cells/infusion) in case 2 , and the characteristics of $\alpha \beta T$ cells prepared from each patient were not significantly changed at the first and fourth cultivation (data not shown). The numbers of white blood cells (WBCs) and $\mathrm{CD}_{4} 5^{+}$leukocytes in peripheral blood did not change after ICI and ACT combination immunotherapy (Fig. 3). The numbers of $\mathrm{CD}^{+}, \mathrm{TCR} \alpha \beta^{+}, \mathrm{TCR} \gamma \delta \mathrm{T}^{+}$, 


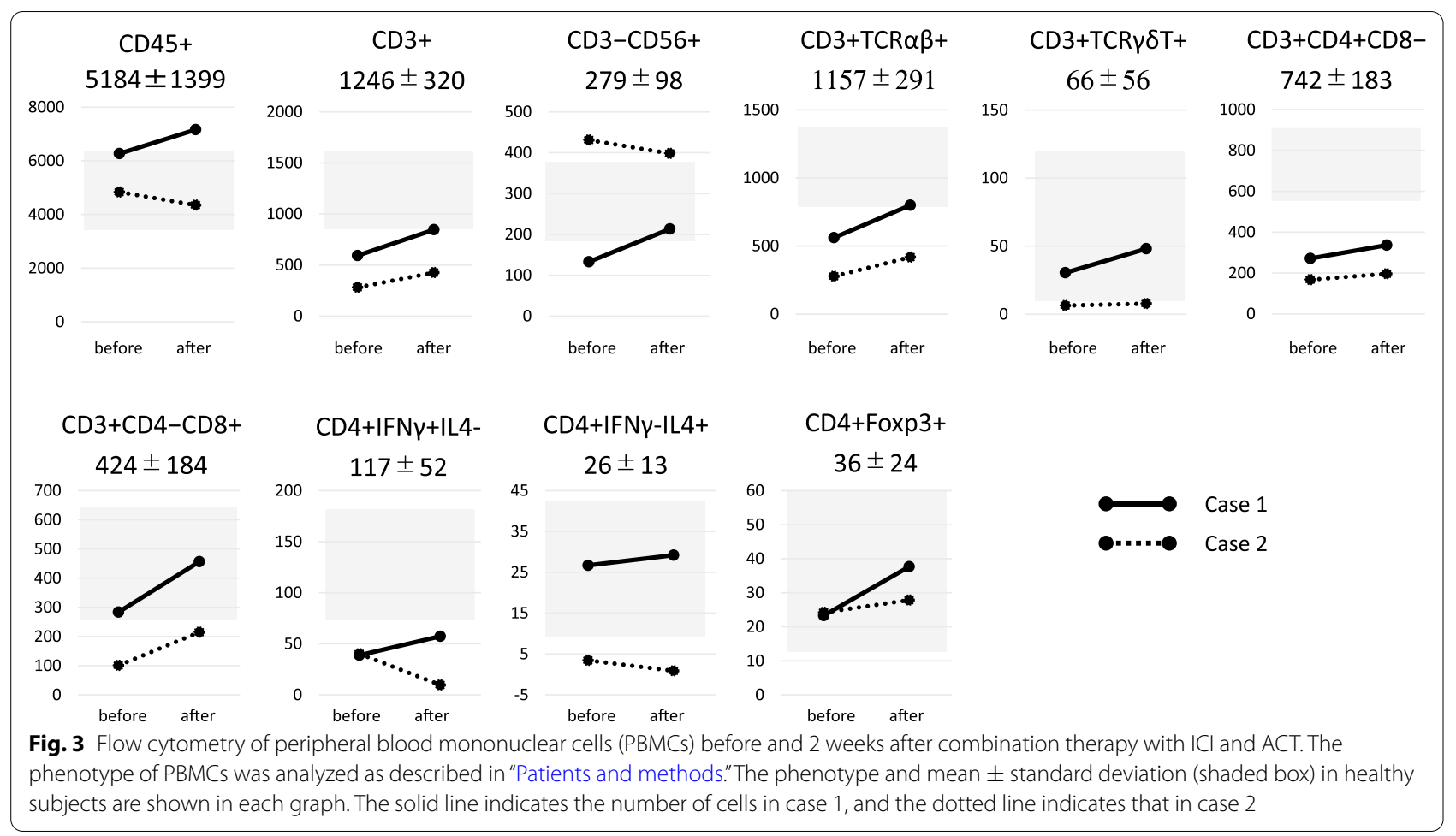

$\mathrm{CD} 4^{+} \mathrm{CD} 8^{-} \mathrm{T}$, and $\mathrm{CD} 4^{-} \mathrm{CD} 8^{+} \mathrm{T}$ cells were significantly lower than those in healthy subjects before ACT [16], and increased after ICI and ACT combination immunotherapy (Fig. 3). There were no significant differences in the numbers of $\mathrm{CD}^{-} \mathrm{CD}^{-} 6^{+}$, IFN- $\gamma+\mathrm{IL}^{-}$(Th1), IFN- $\gamma$-IL4 ${ }^{+}$(Th2), and Foxp3+ (Treg) cells among the $\mathrm{CD}^{+}{ }^{+} \mathrm{CD}^{+}{ }^{+}$subset cells (Fig. 3 ).

\section{Discussion and conclusion}

We describe herein two cases of patients treated with the combination of ACT and an ICI; one patient was treated concurrently with ACT and an ICI, and the other patient obtained a partial response by administration of ACT and a DC vaccine followed by ICI administration for recurrence.

Although grade 1 hypothyroidism occurred in case 1 that required thyroid hormone supplementation, we observed no further severe adverse events in either case. Since we assumed that combination therapy with ACT and the ICI might increase the incidence and severity of adverse events, we used a much lower dose of nivolumab than the standard dose, that is, 0.3 or $0.6 \mathrm{mg} / \mathrm{kg}$ body weight ( $20 \mathrm{mg} / \mathrm{kg}$ body weight or $40 \mathrm{mg} / \mathrm{kg}$ body weight), respectively. The standard dose of nivolumab used in cancer therapy is usually $240 \mathrm{mg} / \mathrm{kg}$ body weight, so the dose administered in this trial was one-sixth or onetwelfth of the standard dose of nivolumab, for which no sufficient clinical data have been reported for evaluating the efficacy of nivolumab for esophageal cancer. However, it has been shown by in vitro analysis that even a low dose of nivolumab, $0.3 \mathrm{mg} / \mathrm{kg}$ body weight, was sufficient to inhibit PD-L1/PD-1 association [17].

Several biomarkers that can predict the clinical response of nivolumab have been reported. PD-L1 expression is one of the candidates, since a number of gastrointestinal cancers overexpress this molecule [18, 19]. Although PD-L1 expression determined by immunohistochemical staining has been correlated with prognosis and response to ICIs in several studies [17, 18], other studies demonstrated ICI efficacy in patients deemed to be PD-L1 negative [20]. Thus, the true relationship between PD-L1 expression and clinical efficacy has not yet been elucidated. Tumor mutation burden (TMB) has been demonstrated to be significantly associated with PD-1 and the PD-L1 blocking response. Cancers that have a higher TMB, that is, a higher neoantigen exposure to the immune system, seem more likely to respond to ICIs [21]. In both patients reported herein, analysis of their tumor specimens showed microsatellite stability and a PDL-1 expression level of $1 \%$ or lower. TILs are also found to be an independent marker for prolonging progression-free survival and overall survival in esophageal cancer, thus indicating the critical role of $\mathrm{T}$ cells in tumor immunity [22]. Nevertheless, these markers do not always determine the treatment response to ICIs, 
suggesting that other factors, such as host immunity, might affect the clinical response to ICIs. For example, an association has been demonstrated between pretreatment lymphocyte count and response to ICIs: patients with higher baseline lymphocyte counts showed better clinical benefits from ICIs [23]. Lymphocytes in peripheral blood have been reported to include $\mathrm{T}$ cells targeting neoantigens derived from tumor cells [13, 24]. Thus, an adequate immune status of $\mathrm{T}$ cells in patients is necessary to obtain better efficacy of ICIs. Our previous studies revealed that the $\mathrm{T}$ cell immune status was impaired in advanced cancer patients and it was restored by ACT, suggesting the beneficial effect of combination therapy with ICIs and ACT [16, 24]. Compatible with these observations, flow cytometric analysis revealed that the numbers of $\mathrm{CD}^{+} \mathrm{T}$ lymphocytes and their subsets, including $\mathrm{TCR} \alpha \beta^{+}, \mathrm{TCR} \gamma \delta \mathrm{T}^{+}, \mathrm{CD} 4^{+} \mathrm{CD} 8^{-} \mathrm{T}$, and $\mathrm{CD} 4^{-} \mathrm{CD} 8^{+} \mathrm{T}$ cells, increased after ICI and ACT combination therapy in both patients (Fig. 3), and it might lead to favorable responses to ICIs.

Although the dose of nivolumab given to both patients was very low, it remains unclear whether clinical responses could be obtained at a much lower dose of the ICI alone or the combination of ACT and the ICI. A controlled study is necessary with a large number of patients to clarify this issue. In the case that even a very low dose of nivolumab is found to be effective, dose escalation studies may be required to reevaluate the doses of ICIs for cancer treatment.

\section{Patients and methods}

\section{Patients}

This study was conducted from September 2017 to March 2019. The patients were administered ACT twice at a 2-3-week interval followed by $0.3-0.6 \mathrm{mg} / \mathrm{kg}$ nivolumab and ACT four times at 2 -week intervals. The institutional review board of the hospital approved the study, and written informed consent was obtained from the patients (clinical study number, UMIN000028756: an exploratory clinical trial on the safety of combination therapy with effector cell therapy and immune checkpoint inhibitors for patients with malignant tumor).

\section{Preparation for ACT}

Activated lymphocytes were generated as previously described [14]. In brief, peripheral blood mononuclear cells (PBMCs) were isolated from the patients' peripheral blood using a Vacutainer (Becton, Dickinson and Company, Franklin Lakes, NJ, USA). The PBMCs were activated in a culture flask with an immobilized monoclonal antibody to CD3 (Jansen-Kyowa, Tokyo, Japan) in HyMedium 930 (Kohjin Bio, Saitama, Japan) containing $1 \%$ autologous serum. The PBMCs were then cultured for 14 days with $700 \mathrm{IU} / \mathrm{ml}$ IL-2 (Proleukin $^{\circledR}$; Chiron, Amsterdam, Netherlands), after which 3-10 × $10^{9}$ cells were harvested and suspended in $50 \mathrm{ml}$ normal saline for intravenous injection. To prepare a dendritic cell (DC) vaccine, PBMCs were collected from the patients by leukapheresis and allowed to adhere to a plastic culture flask. The adherent cell fraction was used for DC culture for 6 days in a medium supplemented with $50 \mathrm{ng} /$ ml IL-4 (Primmune Corp., Osaka, Japan) and $50 \mathrm{ng} / \mathrm{ml}$ granulocyte macrophage colony-stimulating factor (GMCSF) (Primmune Corp.) to generate immature DCs. The DCs were pulsed with antigenic tumor-specific peptides or an autologous tumor lysate and allowed to mature for $24 \mathrm{~h}$. After the culture, $1-10 \times 10^{6}$ mature DCs were harvested and suspended in $1 \mathrm{ml}$ normal saline for subcutaneous injection, then cryopreserved until the day of administration.

\section{Flow cytometry of PBMCs}

Heparinized whole blood was collected from the patients. The phenotype of PBMCs was analyzed by whole-blood staining with OptiLyse C lysis solution [16]. Absolute cell number was determined using Flow-Count ${ }^{\mathrm{TM}}$ fluorospheres as internal standard beads. OptiLyse C, FlowCount beads, and monoclonal antibodies (mAbs) against CD3, CD4, CD8, CD14, CD16, CD19, CD45, CD56, TCR pan $\alpha \beta$, TCR pan $\gamma \delta$, and TCR V $\gamma 9$ were purchased from Beckman Coulter (Brea, CA, USA). Lymphoprep ${ }^{\text {TM }}$ (AxisShield PoC AS, Oslo, Norway) was used with gradient centrifugation to isolate the PBMCs. For Foxp3 staining, the PBMCs were fixed and permeabilized using a fixation/permeabilization kit (BioLegend, San Diego, CA, USA) in accordance with the manufacturer's protocol, and Foxp3 was stained with anti-Foxp3 mAb (clone 259D, BioLegend). For intracellular cytokine production assay, the PBMCs were suspended in a conditioned medium supplemented with $10 \%$ heat-inactivated fetal bovine serum (Invitrogen, Grand Island, NY, USA) containing phorbol 12-myristate 13-acetate (Sigma-Aldrich, St. Louis, MO, USA), ionomycin (Sigma-Aldrich), and brefeldin A (Sigma-Aldrich). The cells were incubated at $37{ }^{\circ} \mathrm{C}$ in a humidified atmosphere with $5 \% \mathrm{CO}_{2}$ for $4 \mathrm{~h}$ for the IFN- $\gamma /$ IL- 4 assay. After the activated cells were fixed and permeabilized, intracellular cytokines were stained with an anti-IFN- $\gamma$ or anti-IL-4 (Beckman Coulter) antibody. A Cytomics FC500 or a Gallios flow cytometer (Beckman Coulter) was used for data acquisition, and the data were analyzed using CXP or Kaluza software (Beckman Coulter). 


\section{Immunohistochemistry}

To measure the PD-L1 expression level in cancer tissue, PD-L1 IHC 22C3 pharmDx (Agilent Technologies, Santa Clara, CA, USA) was used in accordance with the manufacturer's instructions.

\section{Microsatellite instability}

Microsatellite instability (MSI) was determined using a modified version of the pentaplex polymerase chain reaction (PCR) assay as described by Buhard et al. [25] using five markers (NR-21, BAT-26, BAT-25, NR-24, and MONO-27) and analyzed using an ABI PRISM 3100 genetic analyzer (Applied Biosystems, Foster City, CA, USA) in accordance with the manufacturer's instructions.

\begin{abstract}
Abbreviations
PD-1: Programmed death 1; ICl: Immune checkpoint inhibitor; ACT: Adoptive immune cell therapy; PD-L1 and PD-L2: Programmed death ligand-1 and programmed death ligand-2, respectively; TIL: Tumor-infiltrating lymphocyte; TCL: T-cell receptor; IL-2: Interleukin-2; PBMC: Peripheral blood mononuclear cell; DC: Dendritic cell; GM-CSF: Granulocyte macrophage colony-stimulating factor; MSI: Microsatellite instability; CT: Computed tomography; CCRT: Concurrent chemoradiation therapy; DTX: Docetaxel.
\end{abstract}

\section{Acknowledgements}

Not applicable.

\section{Authors' contributions}

$R T, T K, T G, T T$, and SG treated the patients and made the clinical diagnosis. RT, TK, SO, HI, EO, and SG discussed and analyzed the data. RT and SG wrote and revised the manuscript. All authors read and approved the final manuscript.

\section{Funding}

This study did not receive any specific grant from funding agencies in the public, commercial, or not-for-profit sectors.

\section{Availability of data and materials}

The datasets used and/or analyzed during the current study are available from the corresponding author on reasonable request.

\section{Ethics approval and consent to participate}

The institutional review board of the hospital approved the study, and written informed consent was obtained from the patients (clinical study number, UMIN000028756: an exploratory clinical trial on the safety of combination therapy with effector cell therapy and immune checkpoint inhibitors for patient with malignant tumor).

\section{Consent for publication}

Written informed consent was obtained from the patients for publication of this case report and any accompanying images. A copy of the written consent is available for review by the Editor-in-Chief of this journal.

\section{Competing interests}

The authors declare that they have no competing interests.

\section{Author details}

${ }^{1}$ Seta Clinic Group, New Surugadai Bldg. 3F, 2-1-45 Kandasurugadai, Chiyoda-ku, Tokyo 101-0062, Japan. ${ }^{2}$ Department of Next-Generation Cell and Immune Therapy, Graduate School of Medicine, Juntendo University, Yamanoue Bldg. 7F, 3-2-6 Hongo, Bunkyo-ku, Tokyo 113-8421, Japan. ${ }^{3}$ Division of Gastroenterology and Hepatology, Nihon University, 1-6, Kandasurugadai, Chiyoda-ku, Tokyo 101-8309, Japan.
Received: 10 November 2020 Accepted: 14 December 2020

Published online: 08 April 2021

\section{References}

1. Enzinger PC, Mayer RJ. Esophageal cancer. N Engl J Med. 2003;349(23):2241-52.

2. Cohen DJ, Leichman L. Controversies in the treatment of local and locally advanced gastric and esophageal cancers. J Clin Oncol. 2015;33(16):1754-9.

3. Chen DS, Mellman I. Elements of cancer immunity and the cancerimmune set point. Nature. 2017;541(7637):321-30.

4. Tumeh PC, Harview CL, Yearley JH, Shintaku IP, Taylor EJ, Robert L, Chmielowski B, Spasic M, Henry G, Ciobanu V, et al. PD-1 blockade induces responses by inhibiting adaptive immune resistance. Nature. 2014;515(7528):568-71.

5. Nishijima TF, Muss HB, Shachar SS, Moschos SJ. Comparison of efficacy of immune checkpoint inhibitors (ICIs) between younger and older patients: a systematic review and meta-analysis. Cancer Treat Rev. 2016;45:30-7.

6. Kudo T, Hamamoto Y, Kato K, Ura T, Kojima T, Tsushima T, Hironaka S, Hara H, Satoh T, Iwasa S, et al. Nivolumab treatment for oesophageal squamous-cell carcinoma: an open-label, multicentre, phase 2 trial. Lancet Oncol. 2017;18(5):631-9.

7. Shaverdian N, Lisberg AE, Bornazyan K, Veruttipong D, Goldman JW, Formenti SC, Garon EB, Lee P. Previous radiotherapy and the clinical activity and toxicity of pembrolizumab in the treatment of non-small-cell lung cancer: a secondary analysis of the KEYNOTE-001 phase 1 trial. Lancet Oncol. 2017;18(7):895-903.

8. Gibney GT, Weiner LM, Atkins MB. Predictive biomarkers for checkpoint inhibitor-based immunotherapy. Lancet Oncol. 2016;17(12):e542-51.

9. Teng MW, Ngiow SF, Ribas A, Smyth MJ. Classifying cancers based on T-cell infiltration and PD-L1. Cancer Res. 2015;75(11):2139-45.

10. Rosenberg SA, Yang JC, Sherry RM, Kammula US, Hughes MS, Phan GQ Citrin DE, Restifo NP, Robbins PF, Wunderlich JR, et al. Durable complete responses in heavily pretreated patients with metastatic melanoma using T-cell transfer immunotherapy. Clin Cancer Res. 2011;17(13):4550-7.

11. Goff SL, Dudley ME, Citrin DE, Somerville RP, Wunderlich JR, Danforth DN, Zlott DA, Yang JC, Sherry RM, Kammula US, et al. Randomized, prospective evaluation comparing intensity of lymphodepletion before adoptive transfer of tumor-infiltrating lymphocytes for patients with metastatic melanoma. J Clin Oncol. 2016;34(20):2389-97.

12. Tran E, Robbins PF, Lu YC, Prickett TD, Gartner JJ, Jia L, Pasetto A, Zheng Z, Ray S, Groh EM, et al. T-cell transfer therapy targeting mutant KRAS in cancer. N Engl J Med. 2016:375(23):2255-62.

13. Malekzadeh P, Yossef R, Cafri G, Paria BC, Lowery FJ, Jafferji M, Good ML, Sachs A, Copeland AR, Kim SP, et al. Antigen experienced T cells from peripheral blood recognize p53 neoantigens. Clin Cancer Res. 2020;26(6):1267-76.

14. Takimoto R, Kamigaki T, Okada S, Matsuda E, lbe H, Oguma E, Naitoh K, Makita K, Goto S. Efficacy of adoptive immune-cell therapy in patients with advanced gastric cancer: a retrospective study. Anticancer Res. 2017;37(7):3947-54.

15. Dammeijer F, Lievense LA, Veerman GD, Hoogsteden HC, Hegmans JP, Arends LR, Aerts JG. Efficacy of tumor vaccines and cellular immunotherapies in non-small-cell lung cancer: a systematic review and metaanalysis. J Clin Oncol. 2016;34(26):3204-12.

16. Noguchi A, Kaneko T, Naitoh K, Saito M, Iwai K, Maekawa R, Kamigaki T, Goto S. Impaired and imbalanced cellular immunological status assessed in advanced cancer patients and restoration of the T cell immune status by adoptive T-cell immunotherapy. Int Immunopharmacol. 2014;18(1):90-7.

17. Brahmer JR, Drake CG, Wollner I, Powderly JD, Picus J, Sharfman WH, Stankevich E, Pons A, Salay TM, McMiller TL, et al. Phase I study of singleagent anti-programmed death-1 (MDX-1106) in refractory solid tumors: safety, clinical activity, pharmacodynamics, and immunologic correlates. J Clin Oncol. 2010;28(19):3167-75.

18. Herbst RS, Soria JC, Kowanetz M, Fine GD, Hamid O, Gordon MS, Sosman JA, McDermott DF, Powderly JD, Gettinger SN, et al. Predictive correlates 
of response to the anti-PD-L1 antibody MPDL3280A in cancer patients. Nature. 2014;515(7528):563-7.

19. Ohigashi Y, Sho M, Yamada Y, Tsurui Y, Hamada K, Ikeda N, Mizuno T, Yoriki $\mathrm{R}$, Kashizuka H, Yane K, et al. Clinical significance of programmed death-1 ligand-1 and programmed death-1 ligand-2 expression in human esophageal cancer. Clin Cancer Res. 2005;11 (8):2947-53.

20. Wolchok JD, Kluger H, Callahan MK, Postow MA, Rizvi NA, Lesokhin AM, Segal NH, Ariyan CE, Gordon RA, Reed K, et al. Nivolumab plus ipilimumab in advanced melanoma. N Engl J Med. 2013:369(2):122-33.

21. Rizvi NA, Hellmann MD, Snyder A, Kvistborg P, Makarov V, Havel JJ, Lee W, Yuan J, Wong P, Ho TS, et al. Cancer immunology. Mutational landscape determines sensitivity to PD-1 blockade in non-small cell lung cancer. Science. 2015;348(6230):124-8.

22. Rauser $\mathrm{S}$, Langer $\mathrm{R}$, Tschernitz $\mathrm{S}$, Gais $\mathrm{P}$, Jutting $\mathrm{U}$, Feith $\mathrm{M}$, Hofler $\mathrm{H}$, Walch A. High number of $C D 45 R O+$ tumor infiltrating lymphocytes is an independent prognostic factor in non-metastasized (stage I-IIA) esophageal adenocarcinoma. BMC Cancer. 2010;10:608.
23. Diehl A, Yarchoan M, Hopkins A, Jaffee E, Grossman SA. Relationships between lymphocyte counts and treatment-related toxicities and clinical responses in patients with solid tumors treated with PD-1 checkpoint inhibitors. Oncotarget. 2017;8(69):114268-80.

24. Giraldo NA, Becht E, Vano Y, Petitprez F, Lacroix L, Validire P, Sanchez-Salas $R$, Ingels $A$, Oudard $S$, Moatti A, et al. Tumor-infiltrating and peripheral blood T-cell immunophenotypes predict early relapse in localized clear cell renal cell carcinoma. Clin Cancer Res. 2017;23(15):4416-28.

25. Buhard O, Cattaneo F, Wong YF, Yim SF, Friedman E, Flejou JF, Duval A, Hamelin R. Multipopulation analysis of polymorphisms in five mononucleotide repeats used to determine the microsatellite instability status of human tumors. J Clin Oncol. 2006;24(2):241-51.

\section{Publisher's Note}

Springer Nature remains neutral with regard to jurisdictional claims in published maps and institutional affiliations.
Ready to submit your research? Choose BMC and benefit from:

- fast, convenient online submission

- thorough peer review by experienced researchers in your field

- rapid publication on acceptance

- support for research data, including large and complex data types

- gold Open Access which fosters wider collaboration and increased citations

- maximum visibility for your research: over $100 \mathrm{M}$ website views per year

At BMC, research is always in progress.

Learn more biomedcentral.com/submissions 